\title{
Gas-Water-Rock Interactions and Implications for Geoenvironmental Issues
}

\author{
Liangping Li $\mathbb{D}^{1},{ }^{1}$ Meijing Zhang, ${ }^{2}$ and Ming Zhang $\mathbb{D}^{3}$ \\ ${ }^{1}$ Department of Geology and Geological Engineering, South Dakota School of Mines and Technology, Rapid City, SD, USA \\ ${ }^{2}$ Department of Agricultural and Biological Engineering, University of Florida, Gainesville, USA \\ ${ }^{3}$ Faculty of Engineering, China University of Geosciences, Wuhan, China
}

Correspondence should be addressed to Liangping Li; liangping.li@sdsmt.edu

Received 12 September 2018; Accepted 12 September 2018; Published 8 October 2018

Copyright (C) 2018 Liangping Li et al. This is an open access article distributed under the Creative Commons Attribution License, which permits unrestricted use, distribution, and reproduction in any medium, provided the original work is properly cited.

\section{Motivation and Background}

Water and gas, as the two most common fluids and primary geologic forces, are crucial components in various geological processes. Gas-water-rock interactions play indispensable roles in the evolution of geoenvironmental issues. For example, the accurate prediction of groundwater flow and contaminant transport requires a profound understanding of physicochemical processes that occur among liquid, solid, and gas phases [1]. At present, more attention should be paid to gas-water-rock interactions related to the transport and retention of toxic contaminants such as heavy metals and organic contaminants in aquifers and vadose zones, due to the release of toxic contaminants from intensive human activities [2]. In addition, a gas-water-rock reaction might change the stress field, groundwater seepage field, and properties of rocks and soils, which subsequently leads to the instability of slope and landslide hazards [3]. A rapid sliding rock mass is likely to trigger waves or stir the atmosphere generating air blasts and facilitating its transport, both aggravating the hazards.

\section{Contents of the Special Issue}

In the paper "Sources Identification of Nitrogen Using Major Ions and Isotopic Tracers in Shenyang, China," H. Huang et al. used multiproxy analysis in their research (stable isotope analyses in combination with chemical and hydrogeological data of the study area) to investigate the interactions between surface water and groundwater, as well as to identify the source of nitrogen contamination in groundwater in Shenyang City, China. $\delta^{18} \mathrm{O}_{\text {water }}$ and $\delta^{2} \mathrm{H}_{\text {water }}$ were used to determine the amount of surface water that was discharged into groundwater, while $\delta^{18} \mathrm{O}_{\text {nitrate }}$ and $\delta^{15} \mathrm{~N}_{\text {nitrate }}$ were employed to determine the sources of nitrate and ammonium in groundwater, which are the main contaminants in the study area. According to the results, the reducing environment in groundwater may result from the prevailing iron and manganese, occurring from the weathering of minerals and rocks, which prevents the ammonium being oxidized into nitrate. The ratios of the recharge from the Hun River into groundwater were also identified. Multiproxy analysis also indicated that human activities, such as manure and sewage discharge, are the prevailing source of nitrogen in the waters.

In the paper "A Statistical Constitutive Model considering Deterioration for Brittle Rocks under a Coupled Thermal-Mechanical Condition," M. Gao et al. investigated constitutive behaviors of rocks under thermal-mechanical coupling conditions. A statistical damage constitutive model was firstly established on the basis of Weibull's distribution, by considering the thermal effects and crack initiation strength. Then, the parameters of the model were determined and expressed according to the characteristics of the stressstrain curve. Finally, the model was verified by conventional triaxial experiments of granite under thermal-mechanical actions $\left(25 \mathrm{MPa}, 40^{\circ} \mathrm{C}-60^{\circ} \mathrm{C}\right)$. The results show a relatively good coincidence between experimental curves and theoretical curves in the case studies. The validity of the model was therefore confirmed. 
In the paper "Integration of an Iterative Update of Sparse Geologic Dictionaries with ES-MDA for History Matching of Channelized Reservoirs," S. Kim et al. proposed to couple an iterative sparse coding in a transformed space with an ensemble smoother with multiple data assimilation (ES-MDA) for dealing with the non-Gaussian problem. In this approach, discrete cosine transform (DCT) is followed by the repetition of K-singular value composition (K-SVD) for constructing sparse geologic dictionaries that preserve geological features of the channelized reservoir. Two channelized gas reservoirs were used to validate the proposed algorithm and the results show that the integration of DCT and iterative K-SVD improves the matching performance of gas rate, water rate, bottom-hole pressure, and channel properties with geological plausibility.

In the paper "The Monitoring-Based Analysis on Deformation-Controlling Factors and Slope Stability of Reservoir Landslide: Hongyanzi Landslide in the Southwest of China," B. Han et al. conducted a comprehensive analysis to improve the understanding on the deformation characteristics and controlling factors of the Hongyanzi landslide in the Southwest of China. The results indicated that significant deformation occurred during the drawdown period; otherwise, the landslide remained stable. The major reason of the reservoir landslide deformation was the generation of seepage water pressure caused by the rapidly growing water-level difference between inside and outside of the slope. The influences of precipitation and earthquake were insignificant.

In the paper "Hydrochemical Characteristics and Formation of the Madeng Hot Spring in Yunnan, China," Z. Ren et al. investigated the hydrochemical characteristics and formation of the Madeng hot spring. Through field data collection and studies, the temperature of the hot spring is $42.1^{\circ} \mathrm{C}$. The spring water has a $\mathrm{pH}$ value of 6.41 , TDS of $3.98 \mathrm{~g} / \mathrm{L}, \mathrm{F}$ contents of $3.08 \mathrm{mg} / \mathrm{L}$, and $\mathrm{H}_{2} \mathrm{SiO}_{3}$ of $35.6 \mathrm{mg} / \mathrm{L}$. Stable hydrogen and oxygen isotopes indicate that the hot water is of meteoric origin. Groundwater is recharged from the infiltration of precipitation in the mountain regions, undergoes a deep circulation, obtains heat from the heat flow, flows upward along fractures, and emerges as an upflow spring through the Quaternary sand and gravel in the central low-lying river valley.

In the paper "Fluid Geochemistry of Fault Zone Hydrothermal System in the Yidun-Litang Area, Eastern Tibetan Plateau Geothermal Belt," Y. Hou et al. investigated the chemical and isotopic compositions of thermal water in an underexploited geothermal belt in the eastern Tibetan Plateau. By analyzing water samples from 24 hot springs, mostly taken from locations in fault zones, it was revealed that the water chemical types of the hot springs are mainly $\mathrm{Na}-\mathrm{HCO}_{3}$-type water. Besides, water-rock interaction and cation exchange and mixture are the dominant hydrogeochemical processes in the hydrothermal evolution. According to the results, the hydrothermal systems are recharged by the meteoric water and are heated by the different deep, thermally and topographically driven convection heat along faults undergoing subsurface boiling before going back to the surface.
In the paper "Investigation on the Relationship between Wellhead Injection Pressure and Injection Rate for Practical Injection Control in $\mathrm{CO}_{2}$ Geological Storage Projects," B. Bai et al. proposed the complete constraint conditions of wellbore injection and used it to investigate the relationship between wellhead injection pressure and injection rate. The results show that these two parameters were mutually constrained. For a certain injection project, the allowable wellhead injection pressure and injection rate separately formed a continuous interval. A change of one parameter within its allowable interval could also change the other, both forming a closed region. Thus, controlling the wellhead injection parameters in this closed region could simultaneously ensure the effectiveness and the safety of injection.

In the paper "Numerical Investigation into the Evolution of Groundwater Flow and Solute Transport in the Eastern Qaidam Basin since the Last Glacial Period," Q. Hao et al. utilized TOUGHREACT to perform a reactive solute transport simulation and considered the influence of watersoluble components on the fluid density in the aridsemiarid Qaidam basin in the northeastern Tibetan Plateau since the last glacial period. A three-level nested groundwater flow system was developed in the study area. Based on the simulation results, there are significant differences in the flow ranges and velocities of the different groundwater flow systems. The seepage velocity of the local water flow system is significantly higher than that of the intermediate and regional water flow systems. Since the last glacial period, the groundwater in the eastern part of the Qaidam Basin has experienced solute concentration and enrichment. The distributions of the groundwater flow system and solutes have been greatly affected by climate variations in different geological periods. The groundwater in the discharge region is currently in the stage of carbonate precipitation and is far from gypsum and halite precipitation. The findings in this study are useful for sustainable utilization of local groundwater resources and for coping with climate change.

In the paper "Characterization of Microscopic Pore Structures of Rock Salt through Mercury Injection and Nitrogen Absorption Tests," J. Chen et al. collected rock salt samples from the Yunying salt mine of Hubei province in China and implemented high pressure mercury injection, ratecontrolled mercury penetration, and nitrogen absorption tests with them. The pore size distribution was evaluated based on fractal analysis. The results showed that the pore size of rock salt varied from 0.01 to $300 \mu \mathrm{m}$ with a major concentration of pore sizes smaller than $1.00 \mu \mathrm{m}$. The pore's radiuses were mainly distributed within a range between 15 and $50 \mathrm{~nm}$. The research further revealed that the pore channel size of rock salt was randomly distributed, but the distribution of pore throat radius fitted very well with fractal law. By analysis of permeability, it was found that the maximum and medium radiuses of the pore throat had significant impacts while porosity was not apparently related to the permeability of rock salt. The higher the fractal dimension, the higher impacts on the permeability of the small throat was detected and the lower influence on the permeability of the big throat was exhibited. Therefore, the small throat determined majorly the permeability of rock salt. 
In the paper "Interaction between Vetiver Grass Roots and Completely Decomposed Volcanic Tuff under Rainfall Infiltration Conditions," L. Xu et al. identified and clarified the influence of vetiver grass roots on soil properties and slope stability through planting vetiver grass at the Kadoorie Farm in Hong Kong and leaving it to grow without artificial maintenance. Under the natural conditions of Hong Kong, growth of the vetiver grass roots can reach $1.1 \mathrm{~m}$ in depth after one-and-a-half year from planting. The percentage of grain size which is less than $0.075 \mathrm{~mm}$ in rooted soil is more than that of the nonrooted soil. The rooted soil of high finer grain content has a relatively small permeability. As a result, the increase in water content is therefore smaller than that of nonrooted soil in the same rainfall conditions. Shear box test reveals that the vetiver grass roots significantly increased the peak cohesion of the soil. The combined effects of grass roots on hydrological responses and shearing strength significantly stabilized the slope in local rainfall conditions.

In the paper "A Measured Method for In Situ Viscosity of Fluid in Porous Media by Nuclear Magnetic Resonance," Z. Yang et al. established a method for determining the in situ viscosity of fluids in porous media and tested the in situ viscosity spectra of water in tight cores under different displacement conditions. The results show that the in situ viscosity distribution of water in porous media was inhomogeneous, and it was not a constant but was related to the distance between water and rock walls. If the distance was small enough, the viscosity would increase rapidly and be greater than the bulk viscosity.

In the paper "Stability Analysis of Partially Submerged Landslide with the Consideration of the Relationship between Porewater Pressure and Seepage Force," Y. Wang et al. presented a modified mathematical expression for the stability analysis of a partially submerged landslide, based on the relationship between porewater pressures and buoyancy acting on the underwater zone of a partially submerged landslide, and the relationship between porewater pressures, seepage force, and buoyancy acting on the partially submerged zone. The resultant porewater pressures acting on the underwater slice equaled the buoyancy, and the porewater pressures acting on the partially submerged slice were equivalent to the seepage force and the buoyancy. The result showed that there were two equivalent approaches for considering the effect of water on landslide stability in the limit equilibrium method. One was based on total unit weight and porewater pressures, and the other was in terms of the buoyant weight and the seepage force. The study provided a good opportunity for simplifying the complex boundary porewater pressures in limit equilibrium analysis for the stability of the partially submerged landslide.

In the paper " $\mathrm{CO}_{2}$ Leakage-Induced Contamination in Shallow Potable Aquifer and Associated Health Risk Assessment," C. Y. Kim et al. focused on the risk assessment of $\mathrm{CO}_{2}$ leakage in a shallow aquifer. 2D reactive transport models were developed and used to simulate the groundwater contamination. The results show that the movement of leaked $\mathrm{CO}_{2}$ was mainly governed by local flow fields within the shallow aquifer. The dissolution of aquifer minerals and increased permeabilities of the aquifer are caused by the induced low-pH plume. The distribution of the total arsenic plume was similar to the one for the arsenopyrite dissolution. Authors conclude that the shape of the arsenic plume impacts the human health risk.

In the paper "Hydrochemical Characteristics and Evolution of Geothermal Fluids in the Chabu High-Temperature Geothermal System, Southern Tibet," X. Wang et al. presented reasonable reservoir temperatures and cooling processes of subsurface geothermal fluids in the Chabu high-temperature geothermal system in Southern Tibet. It investigated the hydrochemical characteristics of a geothermal spring by analyzing 36 geothermal spring samples, and combining this analysis with cluster analysis of multivariate statistical analysis to reveal the cooling processes of subsurface geothermal fluids. According to the results, the geothermal waters of the research area are generally mixed with the shallow cooler waters from the reservoirs. The major cooling processes of the subsurface geothermal fluids gradually transform from adiabatic boiling to conduction from the central part to the peripheral belt.

In the paper "Impact of Redox Condition on Fractionation and Bioaccessibility of Arsenic in Arsenic-Contaminated Soils Remediated by Iron Amendments: A Long-Term Experiment," Q. Zhang et al. focused on the water-soil interactions related to the transport and retention of heavy metal(loid)s such as arsenic in soils. It investigated the effect of redox condition on arsenic fractions and bioaccessibility in arsenic-contaminated soils remediated by iron grit. Specifically, it investigated arsenic fractions in soils under the anoxic condition and aerobic condition before or after the addition of iron grit. According to the results, the labile fractions of As in soils decreased significantly after the addition of iron grit, while the unlabile fractions of As increased rapidly, and the bioaccessibility of As was negligible after $180 \mathrm{~d}$ incubation. More labile fractions of As in iron-amended soils were transformed into less mobilizable or unlabile fractions with the contact time. The increase of crystallization of Fe oxides, decomposition of organic matter, molecular diffusion, and the occlusion within Fe-(hydr)oxides cocontrolled the transformation of As fractions in iron-amended soils under different redox conditions.

In the paper "Effects of Dissolved Organic Matter on Sorption of Oxytetracycline to Sediments," Z. Wang et al. investigated the effect of two representative dissolved organic matters (DOMs) on the adsorption of oxytetracycline (OTC) to three typical sediments (first terrace sediment, river floodplain sediment, and riverbed sediment). Two typical DOMs were derived from corrupt plants (PDOM) and chicken manure (MDOM). Elemental analysis and threedimensional fluorescence were deployed to elucidate the mechanism of the effect of DOM on the adsorption of OTC to sediments. The samples subjected for testing were collected from the Weihe River, Northwest China. According to the results, the humus-like DOM can promote the adsorption of OTC while the protein-like DOM can inhibit the adsorption of OTC to sediments, which is determined by the aromaticity, hydrophilicity, and polarity of the DOMs.

In the paper "A Regional Scale Investigation on Groundwater Arsenic in Different Types of Aquifers in the Pearl 
River Delta, China," Q. Hou et al. focused on groundwater arsenic and other hydrochemical compositions in various aquifers in the Pearl River Delta. It investigated the source and driving forces of arsenic in different types of aquifers in the Pearl River Delta. Specifically, 399 groundwater samples were collected from various aquifers in the Pearl River Delta, 20 chemical compositions of groundwater samples were analyzed, and the relationship between arsenic and other hydrochemical compositions was evaluated by the principal component analysis (PCA). According to the results, about $9.4 \%$ and $2.3 \%$ of the samples with high concentrations $(>0.01 \mathrm{mg} / \mathrm{L})$ of arsenic were in granular and fissured aquifers, respectively, but no samples with a high concentration of arsenic were in karst aquifers. The source and mobilization of groundwater arsenic in granular aquifers are likely controlled by the following mechanism: organic matter in marine strata was mineralized and this provided electrons for electron acceptors, resulting in the release of $\mathrm{NH}_{4}{ }^{+}$and $\mathrm{I}^{-}$and the reduction of $\mathrm{Fe} / \mathrm{Mn}$ and $\mathrm{NO}_{3}{ }^{-}$, which was accompanied with the mobilization of arsenic from sediments into groundwater.

In the paper "A Coupled One-Dimensional Numerical Simulation of the Land Subsidence Process in a Multilayer Aquifer System due to Hydraulic Head Variation in the Pumped Layer," Y. Wang et al. focused on a case study of land subsidence modeling in China. A numerical model of a coupled one-dimensional multilayer aquifer system is developed. The results show that the pressure head in layers does not rise immediately after pumping ceases. Also, the results show that there is a transition period between land subsidence and rebound. In this transition period, land could continue to subside while the head in the pumped layer starts to recover.

\section{Conflicts of Interest}

The authors declare that there is no conflict of interest regarding the publication of this article.

\section{Acknowledgments}

The guest editorial team would like to thank all the authors for their contributions to this special issue. We also thank anonymous reviewers for their constructive comments which have greatly improved the quality of those papers. We hope that you enjoy reading this special issue that highlights the geoenvironmental issues of gas-water-rock interactions.

Liangping $L i$

Meijing Zhang

Ming Zhang
[2] G. Huang, M. Zhang, C. Liu, L. Li, and Z. Chen, "Heavy metal(loid) s and organic contaminants in groundwater in the Pearl River Delta that has undergone three decades of urbanization and industrialization: distributions, sources, and driving forces," Science of the Total Environment, vol. 635, pp. 913925, 2018.

[3] M. Zhang and M. J. McSaveney, "Is air pollution causing landslides in China?," Earth and Planetary Science Letters, vol. 481, pp. 284-289, 2018.

\section{References}

[1] L. Li, H. Zhou, and J. J. Gómez-Hernández, "A comparative study of three-dimensional hydraulic conductivity upscaling at the macro-dispersion experiment (MADE) site, Columbus Air Force Base, Mississippi (USA)," Journal of Hydrology, vol. 404, no. 3-4, pp. 278-293, 2011. 

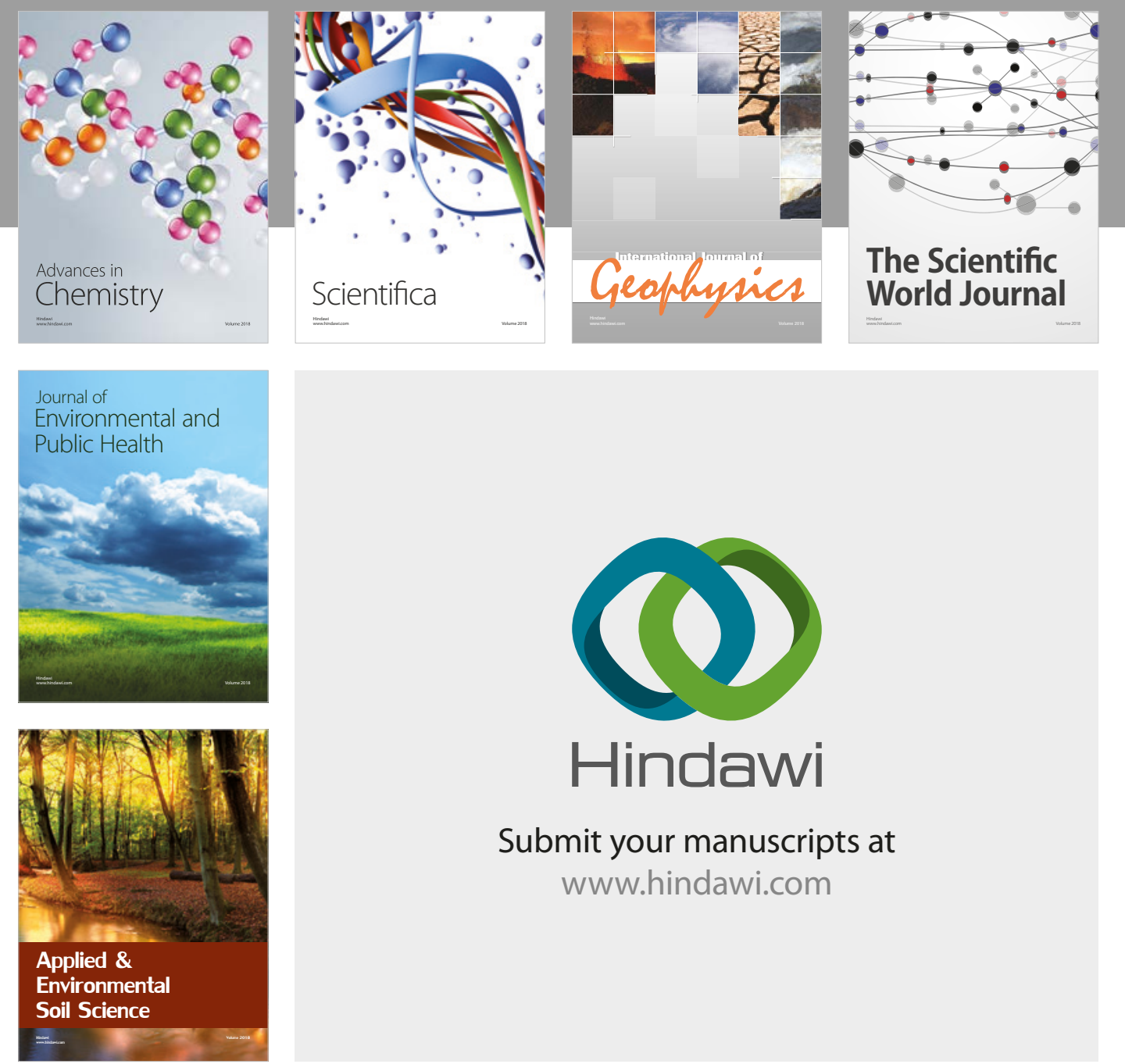

The Scientific

\section{World Journal}
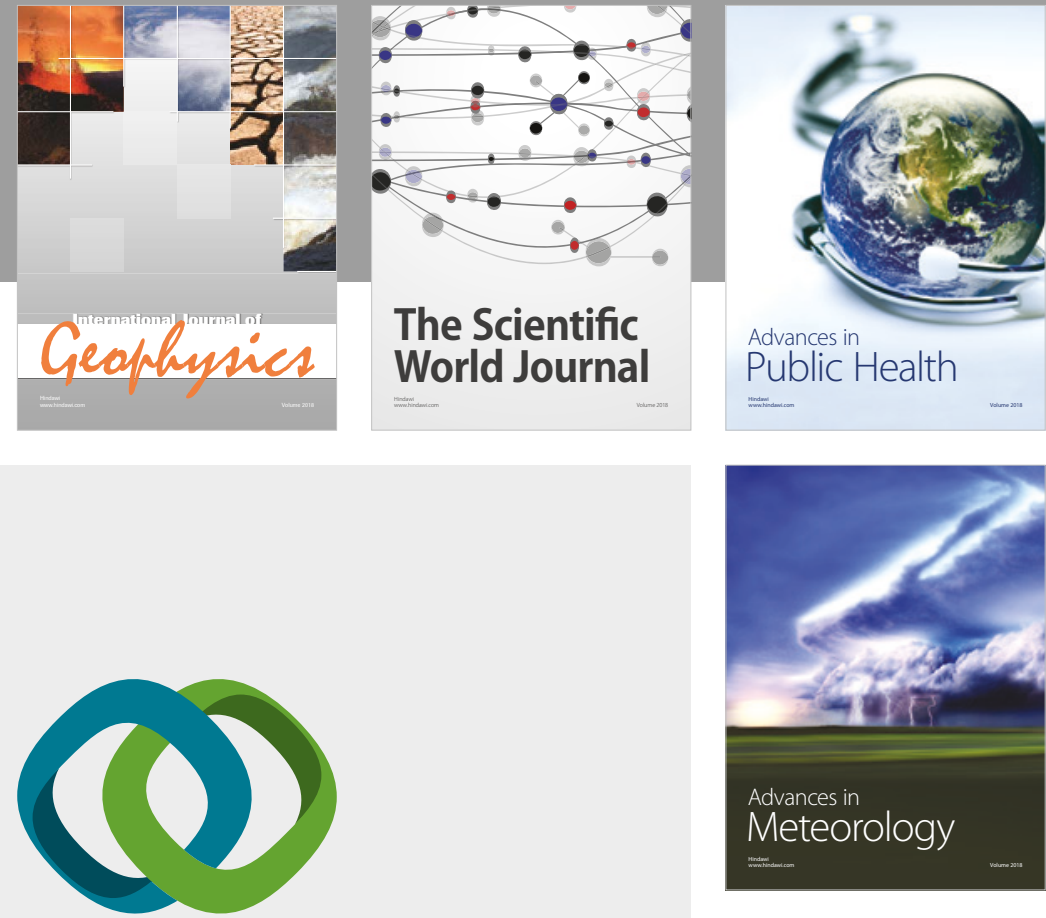

Advan

Public Health

\section{Hindawi}

Submit your manuscripts at

www.hindawi.com
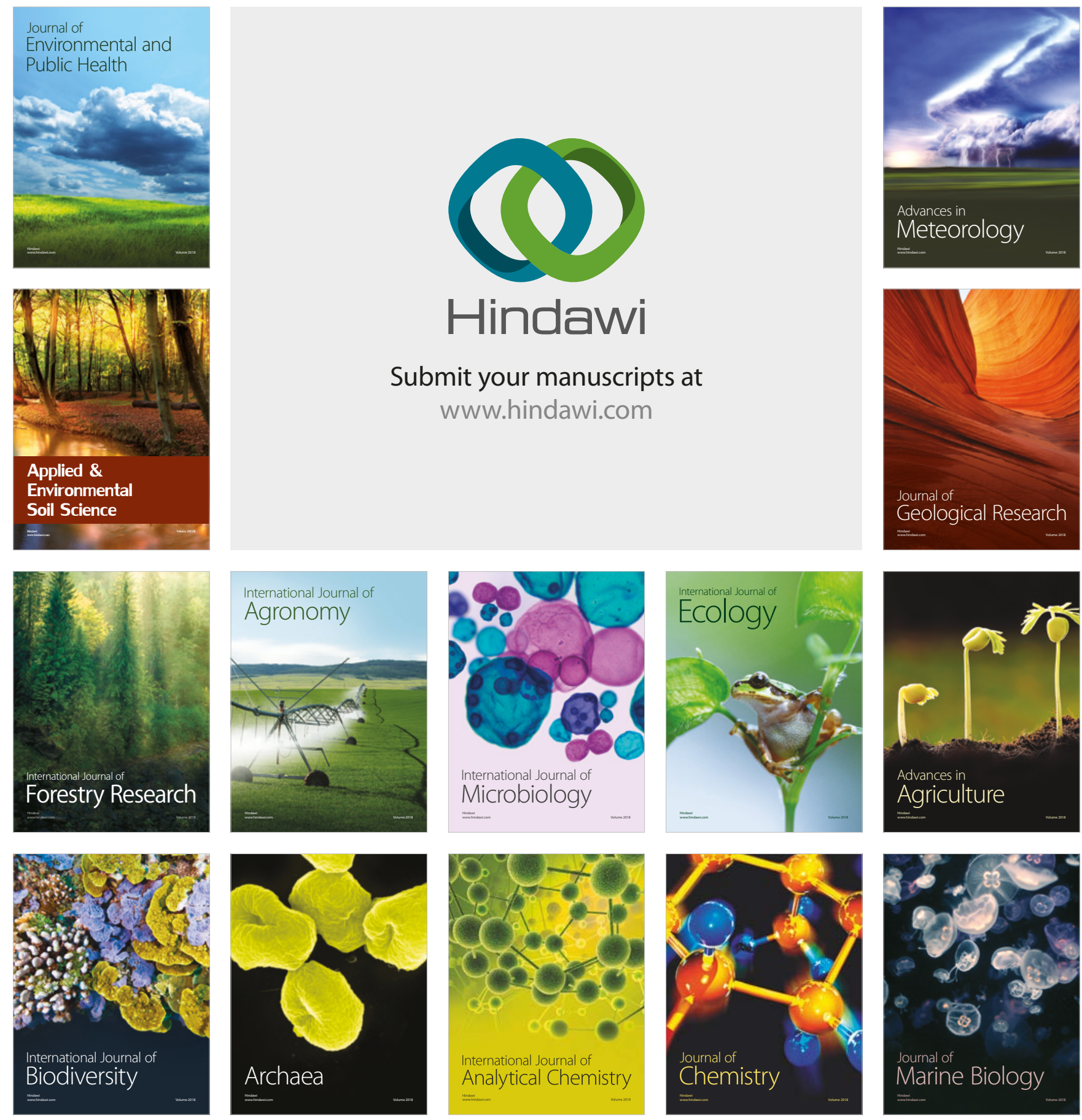